\title{
Rickettsia aeschlimannii sp. nov., a New Spotted Fever Group Rickettsia Associated with Hyalomma marginatum Ticks
}

\author{
LORENZA BEATI, MOSTAPHA MESKINI, BERNADETTE THIERS, AND DIDIER RAOULT* \\ Unité des Rickettsies, Faculté de Médecine, Université de la Mediterranee, 13385 Marseille, France
}

\begin{abstract}
We formally propose the name Rickettsia aeschlimannii sp. nov. for a new spotted fever group (SFG) rickettsia, strain $\mathrm{MC}^{\mathrm{T}} \mathrm{T}^{\mathrm{T}}$, isolated from Hyalomma marginatum marginatum ticks collected in Morocco. This organism shows a typical rickettsial morphology when analyzed by electron microscopy. After characterization by serotyping, sodium dodecyl sulfate-polyacrylamide gel electrophoresis, Western immunoblotting, PCR-restriction fragment length polymorphism (RFLP), pulsed-field gel electrophoresis, and 16S rDNA sequencing, this organism was found to be different from all of the recognized SFG rickettsiae. Identical PCR-RFLP profiles have, however, been found in $H$. marginatum marginatum from Portugal and $H$. marginatum rufipes from Zimbabwe, which suggests that the distribution of this rickettsia reaches from the Mediterranean to southern Africa.
\end{abstract}

Although the first descriptions of Mediterranean spotted fever and its ecology were made in northern Africa (13) and one of the reference strains of Rickettsia conorii is called the Moroccan strain, there have been few recent reports about the ecology and epidemiology of rickettsioses in this area (31). In early studies, all three African spotted fever group (SFG) rickettsioses, Mediterranean spotted fever, South African tick bite fever, and Kenyan tick typhus (25), were attributed to infection with $R$. conorii. The recognized vectors were dog ticks: Rhipicephalus sanguineus in the Mediterranean area (11) and Rhipicephalus simus or Haemaphysalis leachi in the eastern and southern regions of Africa $(22,27)$. When other tick species were found to be infected with rickettsia-like organisms (RLO), they were considered to be "secondary" vectors of $R$. conorii (21). More recently, however, it has been shown that other SFG rickettsiae occur throughout Africa and that several tick species carry rickettsiae different from $R$. conorii $(7,41)$.

The presence of RLO in Hyalomma ticks of Morocco and Sudan was first reported in the 1950s (21). RLO have been detected by PCR and direct immunofluorescence in $H$. impeltatum, $H$. dromedari, and $H$. anatolicum in Egypt; however, they have not been identified (30). During a large-scale field survey in Zimbabwe, hemolymph tests showed that $11 \%$ of Hyalomma marginatum rufipes ticks were infected with RLO (7). Although isolation attempts were unsuccessful, PCR-restriction fragment length polymorphism (RFLP) analysis showed that these ticks contained SFG rickettsiae genotypically similar to a strain (PoTiR8) isolated from $H$. marginatum marginatum ticks from Portugal (2). Strain PoTiR8 has, however, not been further characterized.

In Morocco, $H$. marginatum marginatum is one of the most widely distributed tick species, possibly representing up to $42 \%$ of the tick burden of cattle $(3,32)$. Although in its juvenile stages it usually bites birds, under particular circumstances it may also infest humans (23). We present here the first description of an SFG rickettsial strain (MC16 ${ }^{\mathrm{T}}$ ) isolated from Moroccan $H$. marginatum marginatum. This isolate was compared to the recognized SFG rickettsiae by serotyping, sodium dodecyl sulfate-polyacrylamide gel electrophoresis (SDS-PAGE), Western immunoblotting, electron microscopy, PCR-RFLP,

\footnotetext{
* Corresponding author. Mailing address: Unité des Rickettsies Faculté de Médecine, Université de la Mediterranee, CNRS-UPRES-A 6020, 27, Bd. Jean Moulin, 13385 Marseille, France. Phone: 33/91834375. Fax: 33/91830390. E-mail: Raoult@pacwan.mm-soft.fr.
}

pulsed-field gel electrophoresis (PFGE), and sequencing of the $16 \mathrm{~S}$ rDNA and the citrate synthase genes $(37,38)$. All of these methods indicate that the MC16 ${ }^{\mathrm{T}}$ isolate is a new SFG rickettsia. We therefore propose the name Rickettsia aeschlimannii, in honor of André Aeschlimann, a Swiss zoologist and parasitologist who has made a wide range of scientific contributions in the field of tick-related symbionts and pathogens.

\section{MATERIALS AND METHODS}

Ticks. In March 1992, 40 adult $H$. marginatum marginatum ticks were removed from cattle in the region of $\mathrm{Fez}$, Morocco, and identified according to the usua taxonomic keys (23).

Hemolymph test and isolation attempts. After a 10-min disinfection in iodin ated alcohol, the living ticks were rinsed in distilled water and dried on sterile filter paper. One droplet of hemolymph, obtained by cutting a foreleg of the tick (12), was placed on a slide and stained by the method of Giménez (20). A further droplet of hemolymph was mixed with $500 \mu l$ of brain heart infusion and inoculated into two shell vials containing monolayers of $L 929$ cells. The vials were centrifuged at $700 \times g$ for $1 \mathrm{~h}$, and the supernatant was discarded and replaced with $1 \mathrm{ml}$ of Earle's minimum essential medium (MEM) containing $4 \%$ fetal calf serum and $2 \mathrm{mM}$ L-glutamine $(28,33)$. After 6 days of incubation in a $\mathrm{CO}_{2}$ incubator at $32^{\circ} \mathrm{C}$, the cells were gently scraped from the bottom of the shell via and stained to detect rickettsiae (20). Cells in infected shell vials were detached with trypsin and transferred to empty $25-\mathrm{cm}^{2}$ flasks, where they were subcultured with MEM.

Rickettsiae and antigen production and purification. The following African and European rickettsial strains were grown in order to compare them with ou new isolates: $R$. conorii Moroccan strain ATCC VR-141, Rickettsia helvetica ATCC VR-1375, Rickettsia massiliae ATCC VR-1376, R. massiliae GS (1), Rickettsia sibirica ATCC 232, Rickettsia africae ESF-5 (25), and strain Bar29 (10). Rickettsia slovaca 13B, Israeli spotted fever (ISF) rickettsia strain ISTTCDC1 and $R$. rhipicephali 376 were kindly provided by G. A. Dasch (Naval Medical Research Institute, Bethesda, Md.). For each reference strain and the new isolates, heavily infected $\mathrm{L} 929$ cells from 10 flasks $\left(150 \mathrm{~cm}^{2}\right)$ were harvested, sonicated, and centrifuged at $150 \times \mathrm{g}$ for $15 \mathrm{~min}$. The supernatants were layered onto equal volumes of $25 \%$ sucrose in PBS (phosphate-buffered saline, $\mathrm{pH} 7.4$ ) and centrifuged at $7,000 \times g$ for $30 \mathrm{~min}$. The pellets were pooled and purified on a Renografin density gradient (45). Thereafter, the purified organisms were washed in PBS (three times for $10 \mathrm{~min}$ each time at $17,500 \times \mathrm{g}$ ) and resuspended in distilled water at a concentration of $1 \mathrm{mg} / \mathrm{ml}$ (Total Protein Test; Bio-Rad Laboratories, Richmond, Calif.) for SDS-PAGE and Western blotting. Purification of rickettsiae for PFGE was carried out by following the same procedure but $\mathrm{K} 36$ buffer $\left(16.5 \mathrm{mM} \mathrm{KH}_{2} \mathrm{PO}_{4}, 33.5 \mathrm{mM} \mathrm{K} \mathrm{HPO}_{4}, 100 \mathrm{mM} \mathrm{KCl}, 15.5 \mathrm{mM}\right.$ $\mathrm{NaCl}$ ) was used instead of PBS and distilled water (36). The material collected in a further flask was frozen at $-80^{\circ} \mathrm{C}$ until required for mouse immunization, serologic typing, PCR-RFLP analysis, or nucleotide sequence determination.

Transmission electron microscopy. L929 cells were grown to a confluent monolayer in a 5-cm-diameter petri dish with MEM at $37^{\circ} \mathrm{C}$ in a $\mathrm{CO}_{2}$ incubator. The monolayer was then infected with approximately $10^{3} \mathrm{MC}^{\mathrm{T}} 6^{\mathrm{T}}$ organisms and kept at $32^{\circ} \mathrm{C}$ for 4 days. The infected cells were fixed in a $4 \%$ glutaraldehyde solution (in PBS) for $1 \mathrm{~h}$ at $4^{\circ} \mathrm{C}$, washed with PBS, dehydrated $(70,90$, and $100 \%$ ethanol), and embedded in Epon 812. Thin transverse sections were cut on an LKB Ultratome III microtome and stained with a saturated solution of methanol-uranyl acetate and lead citrate in water. The grids were examined on a JEOL JEM 1200 EX electron microscope. 


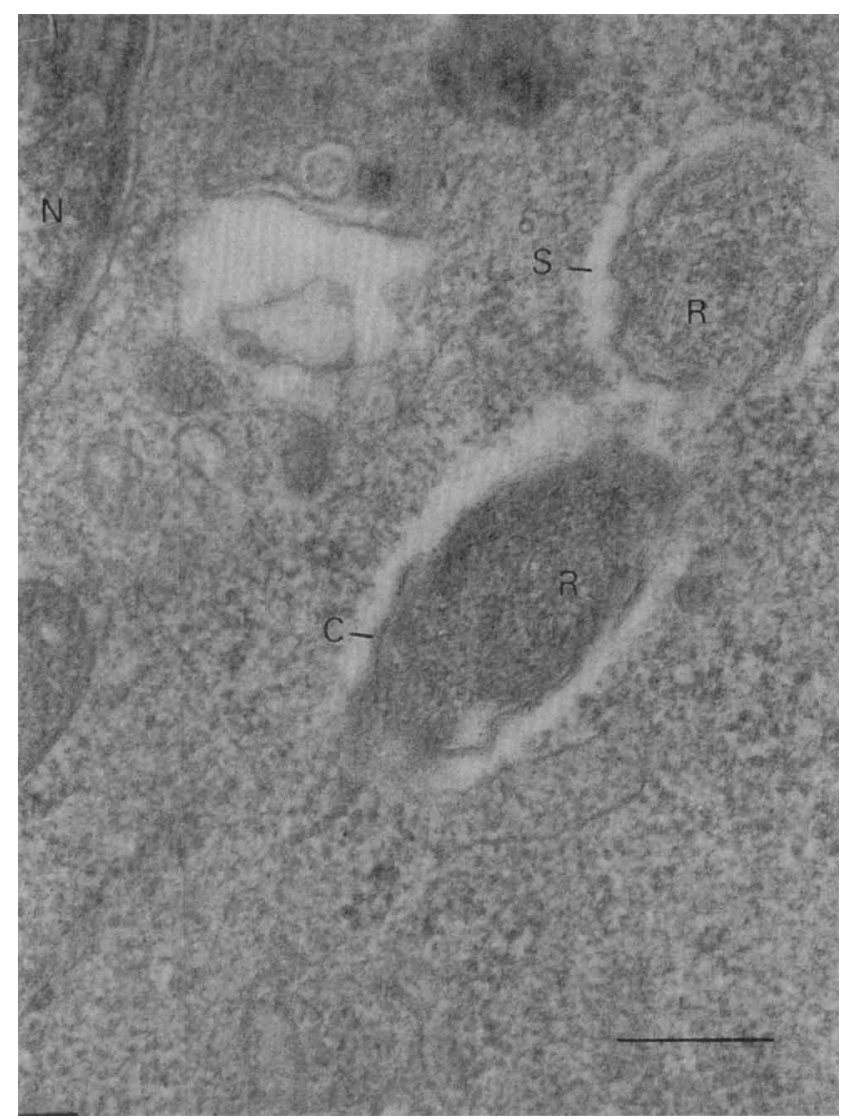

FIG. 1. Electron micrograph of $\mathrm{MC} 16^{\mathrm{T}}$ infecting an $\mathrm{L} 929$ cell. R, rickettsia; $\mathrm{N}$, nucleus; $\mathrm{C}$, trilaminar cell wall; $\mathrm{S}$, translucent zone compatible with the presence of a slime layer. Bar, $0.2 \mu \mathrm{m}$.

Mouse immunization and microimmunofluorescence serotyping (MIF). According to previously described methods (34), $10^{3}$ to $10^{4}$ organisms each of $\mathrm{MC}^{\mathrm{T}}{ }^{\mathrm{T}}$, $R$. conorii, $R$. rhipicephali, $R$. massiliae, Bar29, $R$. helvetica, $R$. slovaca, $R$. sibirica, Israeli SFG rickettsia, and $R$. africae were inoculated intravenously into five Swiss mice on days 0 and 7 . The mice were anesthetized and exsanguinated by cardiac puncture on day 10 , and the sera of each group of five mice were pooled and stored at $-20^{\circ} \mathrm{C}$. For MIF, twofold dilutions (PBS) of the mouse polyclonal sera were reacted with both homologous and heterologous antigens. Fluorescein isothiocyanate-labelled goat anti-mouse immunoglobulins $\mathrm{G}$ and $\mathrm{M}$ (Immunotec, Marseille, France) diluted at $1 / 100$ in PBS were used to detect antibodies, and the highest serum dilutions giving positive reactions were recorded as endpoint titers. Specificity differences (SPDs) were calculated by following previously described methods (34): $\mathrm{SPD}=(\mathrm{Aa}+\mathrm{Bb})-(\mathrm{Ab}+\mathrm{Ba})$, where $\mathrm{Aa}$ (or $\mathrm{Bb})$ is the $-\log _{2}$ of the endpoint titer between serum $\mathrm{A}$ (or $\mathrm{B}$ ) and the homologous antigen, $\mathrm{a}$ (or b), and $\mathrm{Ab}$ (or $\mathrm{Ba}$ ) is the $-\log _{2}$ of the endpoint titer of serum $\mathrm{A}$ (or B) against its heterologous antigen, $b$ (or a). If the SPD is $<3$, the two strains are assumed to belong to a single serotype; if the SPD is $\geq 3$, the serotypes are different.

SDS-PAGE and Western blot immunoassay. For each strain, a 5- $\mu$ l volume of purified organisms was dissolved in $5 \mu$ l of Laemmli (29) solution ( $4 \%$ SDS, $10 \%$ 2-mercaptoethanol, $0.5 \%$ bromophenol blue, $0.125 \mathrm{M}$ Tris hydrochloride [pH 6.8 ], 25\% glycerol) at room temperature and SDS-PAGE was carried out with a $7.5 \%$ separating gel and a $3.9 \%$ stacking gel. The gel was run in a Mini-Protean II cell (Bio-Rad) at $10 \mathrm{~mA}$ in an ice bath, and protein bands were visualized by Coomassie blue staining. A high-range molecular weight standard (Bio-Rad) was used to estimate the molecular weights of the electrophoretic bands. Another identical gel was transferred (42) to nitrocellulose paper in a Trans-blot apparatus (Bio-Rad) at $50 \mathrm{~V}$ for $1 \mathrm{~h}$ in an ice bath. Nonspecific binding sites were blocked overnight with $5 \%$ nonfat dry milk-TBS $(10 \mathrm{mM}$ Tris hydrochloride [pH 7.5], $250 \mathrm{mM} \mathrm{NaCl}, 0.01 \%$ merthiolate). After three 10-min washes in TBS, the nitrocellulose paper was overlaid with the polyclonal serum raised agains $\mathrm{MC}^{\mathrm{T}} \mathrm{T}$, diluted $1 / 100$ in $3 \%$ nonfat dry milk-TBS, and rocked for $2 \mathrm{~h}$. Reactive antibodies were detected with a 1/200 goat anti-mouse globulin-peroxidase conjugate (Immunotec) in 3\% nonfat dry milk-TBS. Following three further 10-min washes in TBS, the bound peroxidase was detected by a solution containing $0.015 \%$ 4-chloro-1-naphthol, $0.015 \%$ hydrogen peroxide, and $16 \%$ methanol in TBS. As soon as the bands became visible, the reactions were stopped with repeated washes in distilled water.

PCR-RFLP. DNA was extracted from cells heavily infected with $\mathrm{MC}^{\mathrm{T}}{ }^{\mathrm{T}}, R$ massiliae, $R$. conorii, $R$. rhipicephali, or Bar29 by using a QiAmp Tissue kit (Qiagen, Hilden, Germany). For each strain, cells harvested from a $25-\mathrm{cm}^{2}$ flask were lysed by following the producer's instructions and the DNA was eluted into $200 \mu \mathrm{l}$ of distilled water. A sample containing $10 \mu \mathrm{l}$ of the extracted DNA, 59.5 $\mu \mathrm{l}$ of distilled water, $10 \mu \mathrm{l}$ of Taq buffer (Perkin Elmer Cetus, Norwalk, Conn.) $10 \mu \mathrm{l}$ of deoxynucleoside triphosphates ( $2 \%$ dATP, $2 \%$ dCTP, $2 \%$ dTTP, and $2 \%$ dGTP in distilled water; Boehringer-Mannheim, Meylan, France), $5 \mu$ l each of citrate synthase primers Rp. CS.877 p-1258n (2 pmol/ $\mu$; Eurogentec, Seraing, Belgium), or $5 \mu \mathrm{l}$ each of $190-\mathrm{kDa}$ protein gene primers Rr. 190.70p-602n (2 $\mathrm{pmol} / \mu \mathrm{l}$; Eurogentec), and $1.25 \mathrm{U}$ of Taq polymerase (Perkin-Elmer Cetus, Branchburg, N.J.) was subjected to 35 cycles of denaturation $\left(95^{\circ} \mathrm{C}\right.$ for $\left.20 \mathrm{~s}\right)$ annealing $\left(50^{\circ} \mathrm{C}\right.$ for $\left.30 \mathrm{~s}\right)$, and sequence extension $\left(72^{\circ} \mathrm{C}\right.$ for $\left.2 \mathrm{~min}\right)$ in a therma cycler (MJ Research DNA Engine; MJ Research, Watertown, Mass.). A further 5 -min extension at $72^{\circ} \mathrm{C}$ completed the enzymatic polymerization. The results of amplification were visualized on a $1 \%$ agarose gel after electrophoretic migration (100 $\mathrm{V}$ for $30 \mathrm{~min}$ ) of $10 \mu \mathrm{l}$ of the amplified material. The agarose gels were stained with ethidium bromide and examined by UV transillumination. Following previously described protocols, $23.3-\mu l$ volumes of the products amplified with the citrate synthase primers (or the $190-\mathrm{kDa}$ protein gene primers) were then digested with $1 \mu \mathrm{l}(10 \mathrm{U})$ of restriction endonuclease $A l u \mathrm{I}$ (or RsaI and $P s t \mathrm{I}$ ) (Boehringer-Mannheim). The digested products were separated on $8 \%$ polyacrylamide gels at $80 \mathrm{~V}$ for 4 to $5 \mathrm{~h}$ (Bio-Rad), stained with ethidium bromide and examined by UV transillumination. DNA molecular weight marker V (Boehringer-Mannheim) and computer-aided densitometry were used to estimate the sizes of the observed DNA fragments (OGEL-DTM program [Quantigel Corporation, Madison, Wis.] connected with "The Imager" system [Appligene Illkirch, France]). With this system, profiles could be compared with those described in other reports $(4-6,8,9,15,17,26,35)$ and with the computerized data collected in the data bank of the Unité des Rickettsies in Marseille.

PFGE. Each of the bacterial suspensions of $\mathrm{MC}^{\mathrm{T}} \mathrm{T}^{\mathrm{T}}, R$. massiliae (type strain $\mathrm{Mtu}^{\mathrm{T}}$ and strain GS), R. rhipicephali, and Bar29 was added to 1 volume of Incer Agarose (FMC Bioproducts, Rockland, Maine) to form agarose blocks and lysed as previously reported (36). The plugs were digested with the endonuclease SmaI (Boehringer-Mannheim), EagI (New England BioLabs, Beverly, Mass.) and BssHII (New England BioLabs). The migrations were carried out in a contour-clamped homogeneous electric field system (CHEF DRII; Bio-Rad Laboratories) at $14^{\circ} \mathrm{C}$ in $0.5 \times$ TBE (Tris-borate-EDTA buffer, $\mathrm{pH} 8$ ). After

TABLE 1. MIF antibody titers and SPDs obtained from reciprocal cross-reactions of mouse antisera with SFG rickettsiae

\begin{tabular}{|c|c|c|c|c|c|c|c|c|c|c|}
\hline \multirow{2}{*}{ Antiserum } & \multicolumn{10}{|c|}{ MIF antibody titer (SPD) } \\
\hline & Strain $\mathrm{MC}^{2} 6^{\mathrm{T}}$ & R. massiliae & Strain Bar29 & R. helvetica & R. conorii & R. sibinica & R. slovaca & ISF rickettsia & R. africae & R. rhipiceph \\
\hline Anti-MC16 ${ }^{\mathrm{T}}$ & $4,096(0)$ & $1,024(3)$ & $256(6)$ & $128(11)$ & $128(12)$ & $64(7)$ & $16(10)$ & $16(11)$ & $16(12)$ & $512(6)$ \\
\hline Anti- $R$. massiliae & $8,192(3)$ & $16,384(0)$ & $4,096(5)$ & $128(13)$ & $128(12)$ & $128(14)$ & $256(7)$ & $64(10)$ & $64(10)$ & $2,048(4)$ \\
\hline Anti-Bar29 & $262,144(6)$ & $131,072(5)$ & $1,048,576(0)$ & $4,096(15)$ & $4,096(14)$ & $16,384(12)$ & $8,192(11)$ & $16(20)$ & $16(21)$ & $131,072(5)$ \\
\hline Anti-R. helvetica & $64(11)$ & $64(13)$ & $32(15)$ & $4,096(0)$ & $32(13)$ & $32(13)$ & $32(9)$ & $32(10)$ & $32(11)$ & $32(8)$ \\
\hline Anti- $R$. conorii & $64(12)$ & $256(12)$ & $128(14)$ & $128(13)$ & $8,192(0)$ & $256(10)$ & $512(6)$ & $1,024(6)$ & $256(9)$ & $256(10)$ \\
\hline Anti-R. sibirica & $16,384(7)$ & $256(14)$ & $512(12)$ & $512(13)$ & $1,024(10)$ & $32,768(0)$ & $4,096(4)$ & $8,192(4)$ & $256(10)$ & $256(12)$ \\
\hline Anti- $R$. slovaca & $256(10)$ & $512(7)$ & $64(11)$ & $256(9)$ & $256(6)$ & $512(4)$ & $1,024(0)$ & $128(6)$ & 64 (11) & $64(10)$ \\
\hline Anti-ISF rickettsia & $512(11)$ & $1,024(10)$ & $256(20)$ & $512(10)$ & $512(6)$ & $1,024(4)$ & $512(6)$ & $4,096(0)$ & $16(14)$ & $64(11)$ \\
\hline Anti-R. africae & $256(12)$ & $1,024(10)$ & $128(21)$ & $256(11)$ & $256(9)$ & $512(10)$ & $32(11)$ & $64(14)$ & $4,096(0)$ & $32(13)$ \\
\hline Anti- $R$, rhipicephali & $256(6)$ & $1,024(4)$ & $512(5)$ & $1,024(8)$ & $64(10)$ & $64(12)$ & $32(10)$ & $64(11)$ & $32(13)$ & $2,048(0)$ \\
\hline
\end{tabular}




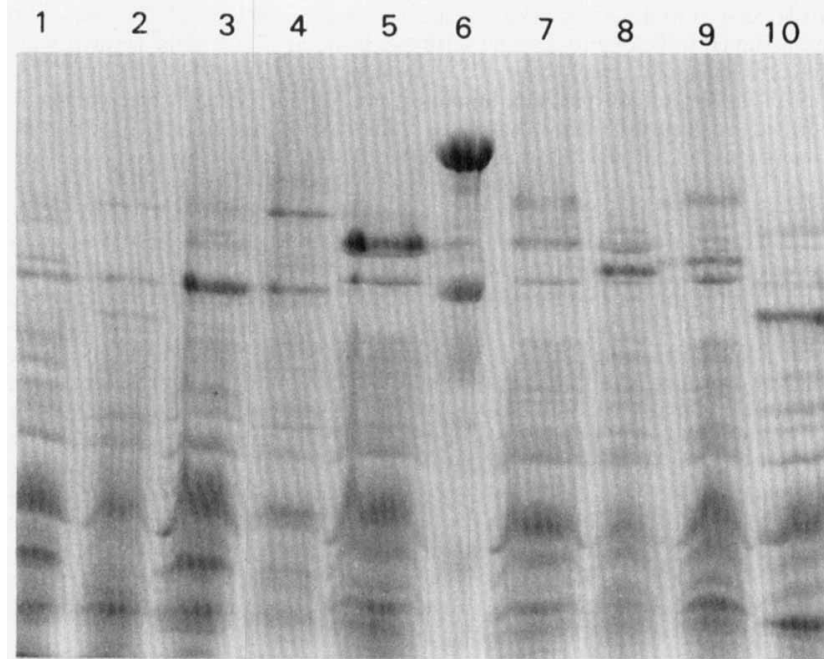

FIG. 2. SDS-PAGE of the antigens of $R$. rhipicephali (lane 1), strain $\mathrm{MC}^{\mathrm{T}}$ (lane 2), strain Bar29 (lane 3), R. massiliae (lane 4), R. conorii (lane 5), R. africae (lane 7), $R$. slovaca (lane 8 ), $R$. sibirica (lane 9), and $R$. helvetica (lane 10). Standard molecular mass markers, from the bottom, 49.5, 80, 116, and $205 \mathrm{kDa}$, were in lane 6.

restriction with Bss HII, the migration conditions were $33 \mathrm{~h}$ at $4.5 \mathrm{~V} / \mathrm{cm}$ with ramped pulse times varying from 5 to $120 \mathrm{~s}$. A low number of bands is commonly observed after digestion with BssHII. Therefore, this enzyme is particularly interesting for evaluation of the overall size of rickettsial genomes. To discriminate all of the bands obtained after restriction with SmaI and EagI, two differen protocols were used for migration of the digests: $19 \mathrm{~h}$ at $5.7 \mathrm{~V} / \mathrm{cm}$ (ramped pulse times from 3 to $10 \mathrm{~s}$ ) and a further $10 \mathrm{~h}$ at $5.4 \mathrm{~V} / \mathrm{cm}$ (ramped pulse times from 20 to $40 \mathrm{~s}$ ) or $8 \mathrm{~h}$ at $6 \mathrm{~V} / \mathrm{cm}$ (ramped pulse times from 1 to $3 \mathrm{~s}$ ) followed by $9 \mathrm{~h}$ at $6 \mathrm{~V} / \mathrm{cm}$ (ramped pulse times from 1 to $5 \mathrm{~s}$ ). Low-range and lambda ladde PFGE markers (New England BioLabs) were used for estimation of the molecular sizes of the digested products. Computer-aided estimation of the molecular weights was performed as described for PCR-RFLP analysis.

$16 S$ rRNA gene sequencing and data analysis. The DNA was extracted from MC16 ${ }^{T}$ as described in the PCR-RFLP protocol. The primer pairs used for the amplification and sequencing of the gene encoding the 16S rRNA have been previously described (37). The amplicons were sequenced by using an Autoread sequencing kit (Pharmacia, St. Quentin-Yvelines, France). The sequencing reactions were resolved on a Readymix acrylamide gel (Pharmacia) in an A.L.F. automated DNA sequencer (Pharmacia). The sequence of the 16S rRNA gene of $\mathrm{MC}^{\mathrm{T}}{ }^{\mathrm{T}}$ was aligned with the corresponding sequences of the other SFG rickettsiae (37) by using the Clustal (version V) alignment program of the BISANCE software package (14). Levels of similarity between pairs of sequences were determined by using DNASIS (Hitachi Software Engineering America Ltd., Brisbane, Calif.). A matrix of evolutionary distances was derived from the alignment (DNADIST, PHYLIP 3.4 software), and a tree was inferred from these distances by using the neighbor-joining method (PHYLIP) $(18,24,39)$.

\section{RESULTS AND DISCUSSION}

Hemolymph test and isolation attempts. Six of 40 ticks were found to be infected with RLOs. This infection rate of $15 \%$ is consistent with the infection rates of $H$. marginatum rufipes ticks in Zimbabwe (6 to $14 \%$ ) and H. marginatum marginatum ticks in Portugal. However, in Portugal it has been observed that the infection rate may vary from 11 to $30 \%$, depending on the geographic area (1a). Five isolates were obtained after centrifugation of the hemolymph on shell vials; however, cell lines were found to be contaminated with Mycoplasma spp., and after decontamination (16), only a single isolate, $\mathrm{MC}^{\mathrm{T}} \mathrm{T}^{\mathrm{T}}$, could be recovered. The contaminated strains were, however, analyzed by PCR-RFLP and had profiles identical to that of strain $\mathrm{MC}^{\mathrm{T}}{ }^{\mathrm{T}}$.

Electron microscopy. Strain $\mathrm{MC}^{\mathrm{T}} \mathrm{T}^{\mathrm{T}}$ is an intracellular organism which occurs free in the cytoplasm of its host cell (Fig. 1 ). At a higher magnification, $\mathrm{MC} 16^{\mathrm{T}}$ shows typical rickettsial morphology, with a trilaminar cell wall surrounded by a translucent area compatible with the presence of an outer slime layer (Fig. 1). The length of $\mathrm{MC}^{\mathrm{T}}{ }^{\mathrm{T}}$ cells varies from 0.7 to 1.1 $\mu \mathrm{m}$, and the mean diameter is $0.3 \mu \mathrm{m}$.

MIF. Calculated SPDs between strain $\mathrm{MC}^{\mathrm{T}}{ }^{\mathrm{T}}$ and the other considered SFG rickettsiae were all $\geq 3$, indicating that $\mathrm{MC}^{\mathrm{T}} 6^{\mathrm{T}}$ is a new SFG serotype (Table 1).

SDS-PAGE and Western immunoblotting. Although the $\mathrm{MC}^{\mathrm{T}}{ }^{\mathbf{T}}$ antigenic profile shares some species-specific high-molecular-weight bands with $R$. massiliae and strain Bar29, its migration patterns are unique and easy to differentiate from those of all other SFG rickettsiae. The approximate molecular masses of the species-specific bands have been evaluated as follows: $(116,120), 140$, and $145 \mathrm{kDa}$ for $R$. rhipicephali; 95 , (116), and $150 \mathrm{kDa}$ for $\mathrm{MC}^{\mathrm{T}}$; (116), 135, 140, and $150 \mathrm{kDa}$ for Bar29; 110, (116), 130, (150), and $160 \mathrm{kDa}$ for $R$. massiliae; 120 and (135) kDa for $R$ conorii; $120,(138)$, and $155 \mathrm{kDa}$ for $R$. africae; 120, (125), 135, and $140 \mathrm{kDa}$ for $R$. slovaca; (120), 130 , and $155 \mathrm{kDa}$ for $R$. sibirica; and $(90,120)$, and $140 \mathrm{kDa}$ for $R$. helvetica (the more prominent bands are in parentheses) (Fig. 2).

By Western blotting, anti-MC16 ${ }^{\mathrm{T}}$ antibodies reacted with low-molecular-mass bands $(<50 \mathrm{kDa})$ of each of the rickettsiae. Cross-reactions with high-molecular-weight species-specific antigens were found only with $R$. massiliae, $R$. rhipicephali, and strain Bar29. The migration patterns of the cross-reacting bands revealed were different, however, allowing one to distinguish these four rickettsiae (Fig. 3).

PCR-RFLP. After amplification with the citrate synthase primers and digestion with $A l u \mathrm{I}$, the profile of $\mathrm{MC}^{\mathrm{T}}{ }^{\mathrm{T}}$ was identical to that of the other classical SFG rickettsiae $(45,95$, 105 , and $135 \mathrm{bp}$ ) (Fig. 4). The 190-kDa protein gene fragment of $\mathrm{MC} 6^{\mathrm{T}}$ showed a profile identical to that of $R$. rhipicephali when digested with $R s a \mathrm{I}(95,106,118$, and $220 \mathrm{bp})$. Following restriction with Pst $\mathbf{I}$, however, the profile was different from

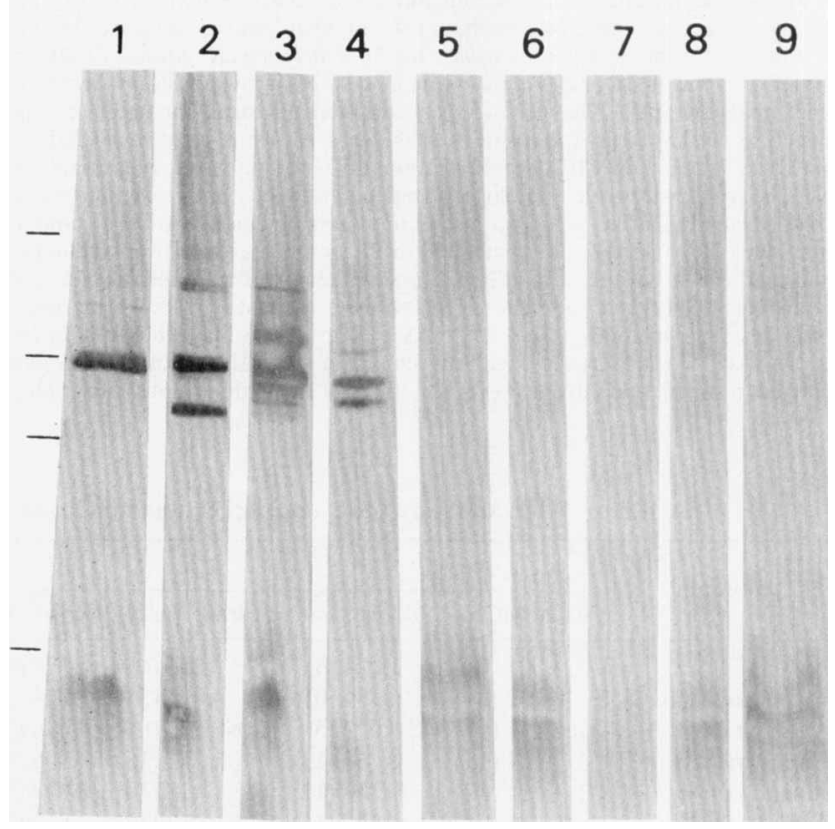

FIG. 3. Western immunoblot assay. Antibodies of anti-MC16 ${ }^{\mathrm{T}}$ sera reactive with $R$. rhipicephali (lane 1), strain $\mathrm{MC}^{\mathrm{T}} 6^{\mathrm{T}}$ (lane 2), strain Bar29 (lane 3), $R$. massiliae (lane 4), $R$. conorii (lane 5), $R$. africae (lane 6), $R$. slovaca (lane 7), $R$. sibirica (lane 8), and $R$. helvetica (lane 9). The bars on the left correspond to molecular masses (from the bottom, 49.5, 80, 116, and $205 \mathrm{kDa}$ ). 


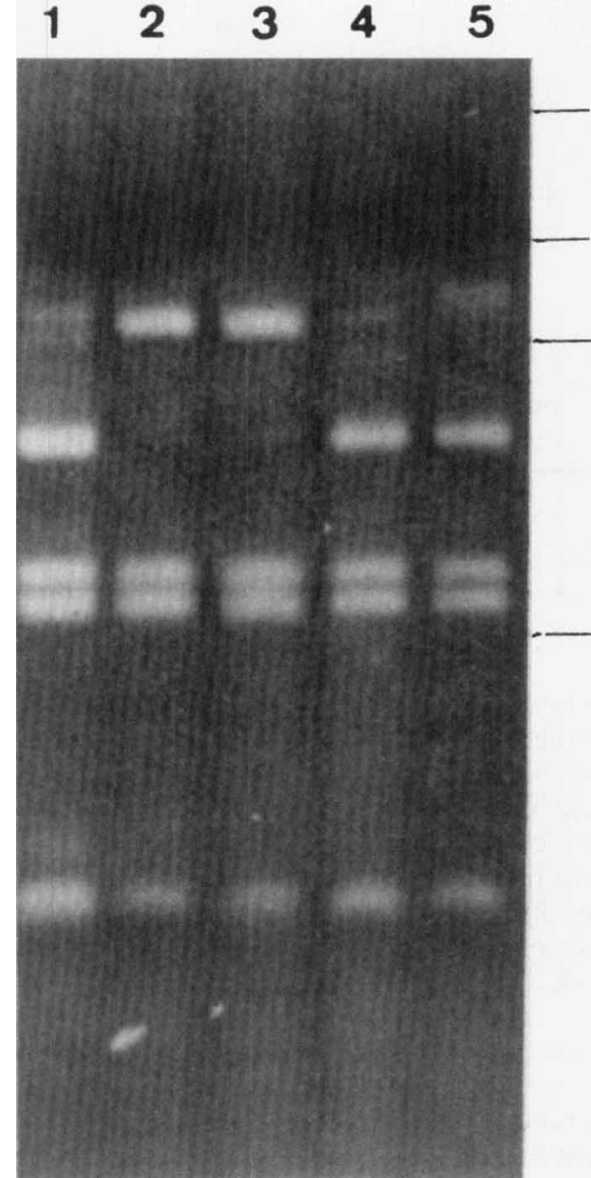

FIG. 4. Ethidium bromide-stained profiles of DNA fragments of strain $\mathrm{MC}^{\mathrm{T}}{ }^{\mathrm{T}}$ (lane 1), R. massiliae (lane 2), strain Bar29 (lane 3), R. rhipicephali (lane 4 ), and $R$. conorii (lane 5) amplified with the citrate synthase primers and digested with $A l u \mathrm{I}$. Molecular size standards are represented by the bars on the right (from the bottom, 79, 162, 210, and $291 \mathrm{bp}$ ).

that of $R$. rhipicephali (260 and $280 \mathrm{bp}$ ) and similar to that of $R$. slovaca and $R$. japonica $(125,165$, and $265 \mathrm{bp})(15)$. This combination of PCR-RFLP migration patterns (Fig. 5 and 6) has already been observed during PCR-RFLP analysis of crude extracts of Zimbabwean $H$. marginatum rufipes (7) and Portuguese Hyalomma isolate PoTiR8 (2).

PFGE. After restriction of the whole genome with BssHII, the genome size of $\mathrm{MC}^{\mathrm{T}}{ }^{\mathrm{T}}$ could be estimated to be $1,336 \mathrm{~kb}$ (Fig. 7), suggesting that $\mathrm{MC}^{\mathrm{T}}{ }^{\mathrm{T}}$, like strain Bar29, R. massiliae, and $R$. helvetica, is characterized by a genome size slightly greater than that of the other SFG rickettsiae $(1,216$ to 1,289 kb) (36). PFGE results obtained after restriction with Bss HII, $S m a \mathrm{I}$, and EagI show that $\mathrm{MC}^{\mathrm{T}}{ }^{\mathrm{T}}$ is clearly different from other SFG rickettsiae, including the closely related species $R$. rhipicephali and $R$. massiliae and strain Bar29 (Fig. 8).

$16 S$ rRNA gene sequencing and data analysis. A 1,432-bp sequence, representing $95 \%$ of the entire $16 \mathrm{~S}$ rRNA gene, was generated for $\mathrm{MC}^{\mathrm{T}}$ and has been deposited in the GenBank database under accession number U74757. Comparison of $16 \mathrm{~S}$ rRNA gene sequences derived from SFG species revealed an high level of similarity between strain $\mathrm{MC}^{1} 6^{\mathrm{T}}$ and strain Bar29 (99.6\%), R. massiliae (99.5\%), and R. rhipicephali (99.6\%). As already pointed out $(25,37)$, the levels of $16 \mathrm{~S}$ rRNA similarity among SFG rickettsiae are all very high. Between $\mathrm{MC}^{\mathrm{T}} 6^{\mathrm{T}}$ and the other SFG rickettsiae, similarity varies from $98 \%$ (Rickett- sia akari) to $99.4 \%$ ( $R$. conorii, $R$. japonica, and $R$. slovaca). Similarly, evolutionary distances between $\mathrm{MC}^{\mathrm{T}} \mathrm{6}^{\mathrm{T}}$ and the other SFG rickettsiae must also be considered to be very low, varying from $0.0199 \times 10^{3}$ nucleotides with the more distant species $R$. akari to $0.0042 \times 10^{3}$ to $0.0049 \times 10^{3}$ nucleotides with $R$. massiliae, $R$. rhipicephali, and strain Bar29. The tree inferred from the distance matrix (Fig. 9) suggests that strain $\mathrm{MC} 6^{\mathrm{T}}$ clusters with $R$. rhipicephali, $R$. massiliae, strain Bar29, and $R$. montana. Although the topology of this tree has no statistical support (bootstrap values are $<80 \%$ ) and must therefore be considered with the greatest caution, the clustering of $\mathrm{MC}^{\mathrm{T}} \mathrm{T}^{\mathrm{T}}$ with at least $R$. rhipicephali, $R$. massiliae, and strain Bar29 has been confirmed by a statistically supported phylogenetic analysis based on comparison of citrate synthase gene sequences (GenBank accession numbers for the citrate synthase genes: $R$. rhipicephali, U59721; $R$. massiliae, U59719; strain Bar29, U59720; strain MC16 $^{\mathrm{T}}$, U59722) (38). Comparison of the citrate synthase genes provides stronger statistical support for the topology of the deeper branches of the tree, including the "MC16 ${ }^{\mathrm{T}}$ cluster." Nodes at this branching level are characterized by bootstrap values varying from 95 to $96 \%$ (38). Interestingly, by Western blot immunoassay, strain $\mathrm{MC}^{2} 6^{\mathrm{T}}, R$. massiliae, $R$. rhipicephali, and strain Bar29 are the only organisms that have antigenic epitopes in common in the high-molecular-weight protein bands.

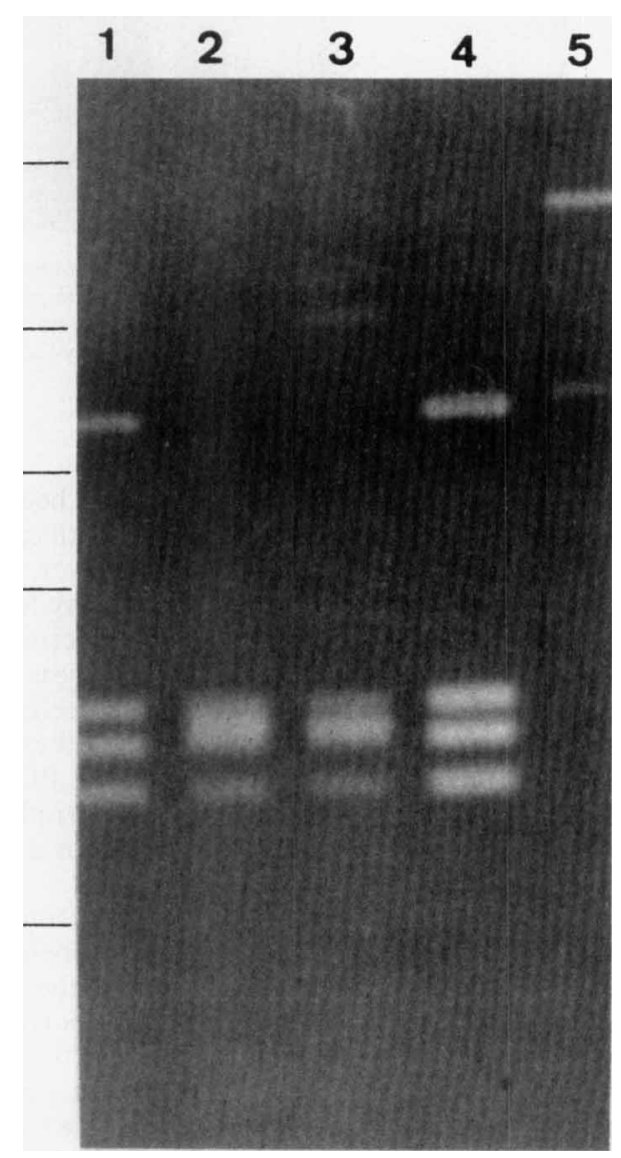

FIG. 5. Ethidium bromide-stained profiles of DNA fragments of strain $\mathrm{MC}^{\mathrm{T}}{ }^{\mathrm{T}}$ (lane 1), R. massiliae (lane 2), strain Bar29 (lane 3), R. rhipicephali (lane 4 ), and $R$. conorii (lane 5) amplified with the 190-kDa protein primers and digested with RsaI. Molecular size standards are represented by the bars on the left (from the bottom, 79, 162, 210, 291, and $392 \mathrm{bp}$ ). 


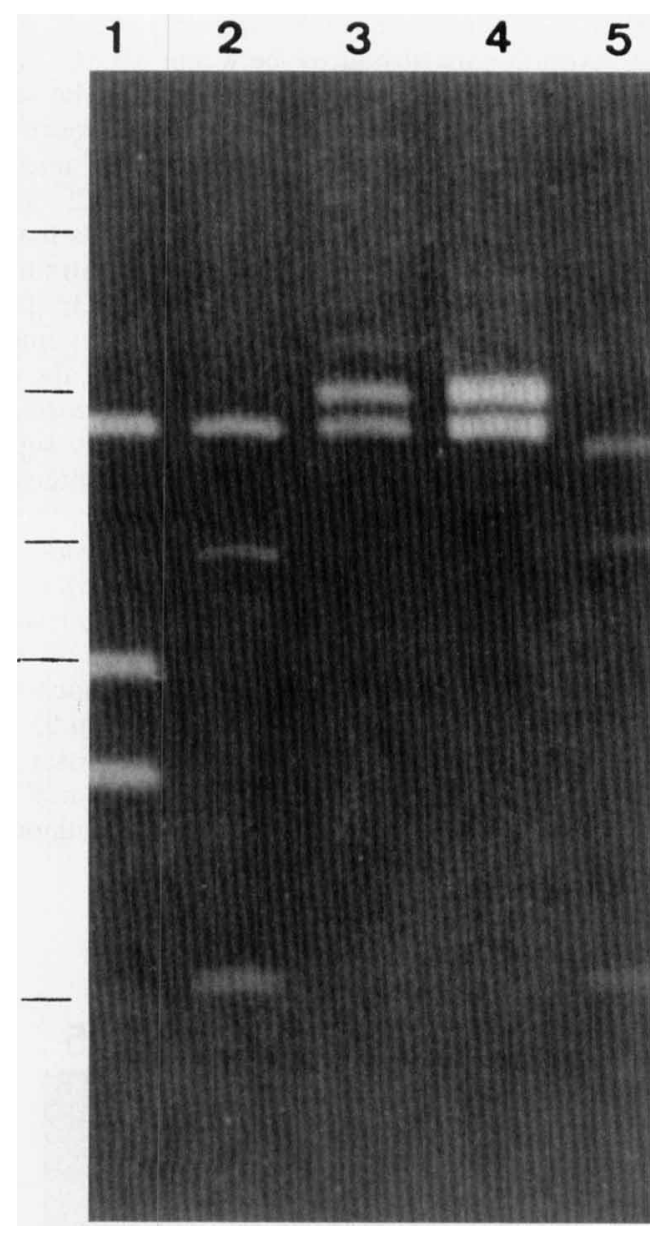

FIG. 6. Ethidium bromide-stained profiles of DNA fragments of strain $\mathrm{MC}^{\mathrm{T}} \mathrm{T}^{\mathrm{T}}$ (lane 1), R. massiliae (lane 2), strain Bar29 (lane 3), $R$. rhipicephali (lane 4 ), and $R$. conorii (lane 5) amplified with the $190-\mathrm{kDa}$ protein primers and digested with PstI. Molecular size standards are represented by the bars on the left (from the bottom, 79, 162, 210, 291, and $392 \mathrm{bp}$ ).

Justification for a new species. MIF has long been considered the reference method for rickettsial identification and classification (34). This method does not, however, fulfill the polyphasic criteria generally accepted as necessary for the description of new bacterial species $(19,44)$. Furthermore, compared with other genotypic and phenotypic analysis methods, MIF is a fastidious and sometimes hazardous technique, the use of which can no longer be justified. All other analysis, including SDS-PAGE, Western immunoblotting, PCR-RFLP, PFGE, and 16S rRNA gene sequencing, concurred with the MIF results in indicating that the $\mathrm{MC}^{1} 6^{\mathrm{T}}$ strain is a new rickettsial pheno- and genotype.

Fragmentary data on DNA-DNA homology among SFG rickettsiae indicate that most of these organisms belong to the same species (43), an observation supported by the high level of similarity observed among SFG rickettsial 16S rRNA gene sequences (37). It has been suggested, however, that bacterial species identification cannot be confidently made on the basis of phylogenetic analysis of $16 \mathrm{~S}$ rDNA sequences which share a level of similarity of $>97 \%$ (40). It has also been observed (25) that the species identification criterion of $>70 \%$ DNA-DNA homology, which was initially proposed for the classification of enterobacteria, may not be suitable to the classification of rickettsiae. Moreover, SFG rickettsiae are strictly intracellular

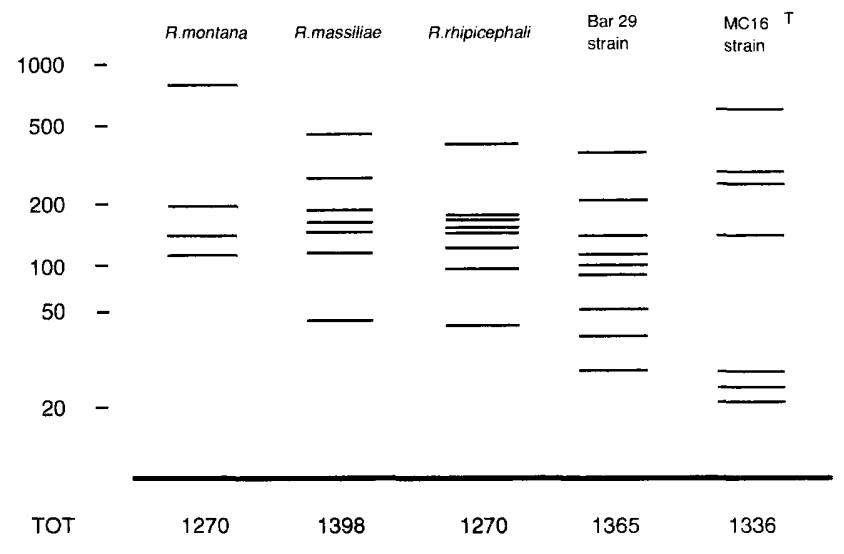

FIG. 7. Schematic representation of the PFGE profiles obtained after digestion of the rickettsial genome with BssHII. TOT, total.

bacteria whose main hosts and reservoirs are hard-tick species. Although the relationship between rickettsiae and ticks is not necessarily obligately specific, some rickettsiae have never been found in more than one tick species, including strain $\mathrm{MC}^{\mathrm{T}}{ }^{\mathrm{T}}$, which has been found to be associated only with $H$. marginatum ticks. Furthermore, there have been no reports of more than one rickettsial strain being harbored by the same tick specimen. Although the possibility of horizontal transmission of rickettsiae through infected vertebrates or cofeeding processes cannot be completely excluded, the fact that rickettsiae are maternally transmitted strongly suggests that rickettsial lineages can be considered to occupy isolated evolutionary niches within specific tick lines. Within this niche, rickettsiae would have scarce opportunity for recombination by genomic exchange with other, related bacteria. As formal criteria for the definition of rickettsial species have yet to be defined, we

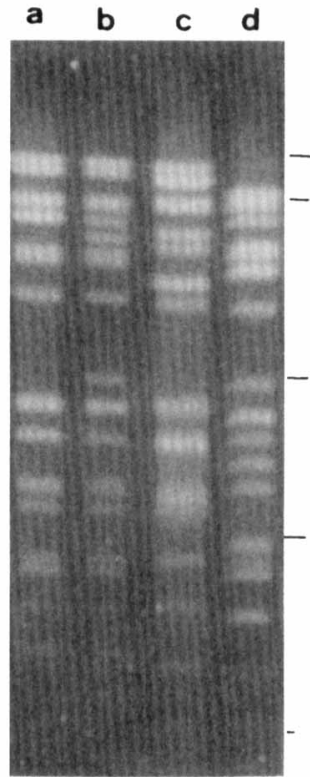

A

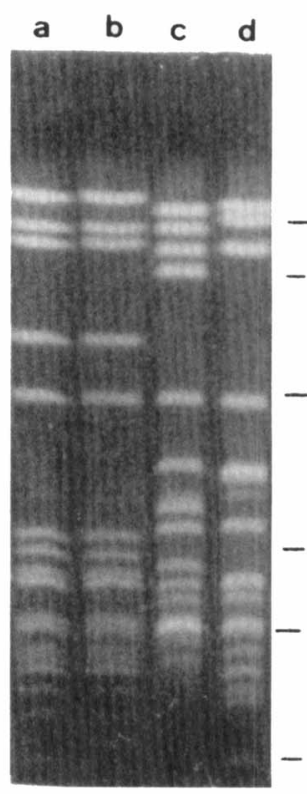

B
FIG. 8. Ethidium bromide-stained PFGE profiles of strain GS (lanes a), $R$ massiliae (lanes b), strain MC16 (lanes c), and strain Bar29 (lanes d) digested with $S m a I$ (A) and EagI (B). Molecular sizes are marked on the right (from the bottom, 9, 23, 48, 97, 145, and $>200 \mathrm{~kb}$ ). 


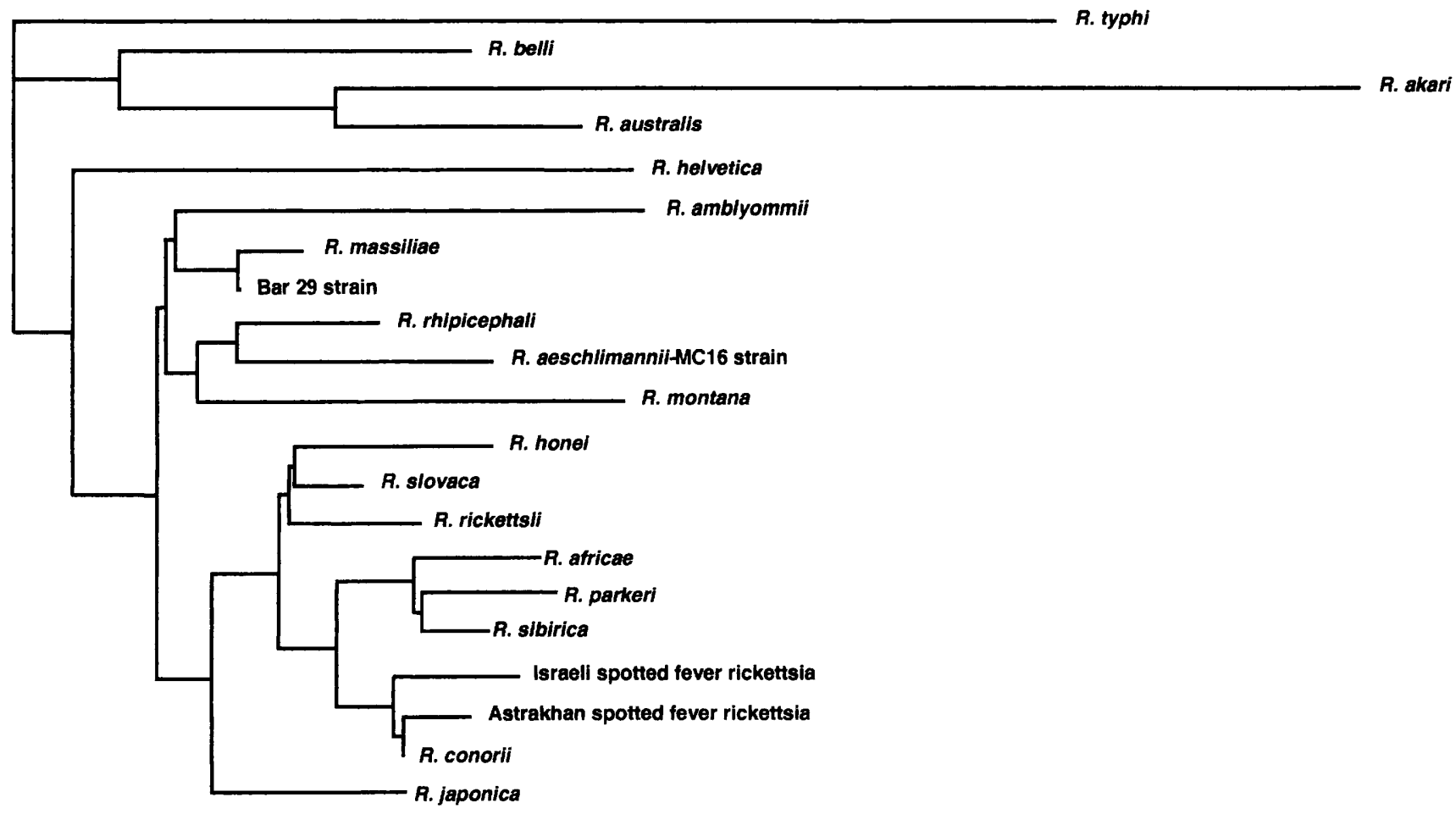

0,001 knuc

FIG. 9. Phylogenetic tree for SFG rickettsiae derived from the 16S rRNA gene. The sequence of Rickettsia typhi was used as an outgroup. Evolutionary distances were determined by the method of Kimura, and the tree was constructed by the neighbor-joining method (39). knuc, $10^{3}$ nucleotides.

believe that a polyphasic approach to SFG taxonomy, based on phenotypic, genotypic, and ecological data, is the most suitable (25). On the basis of these considerations, we propose that strain $\mathrm{MC}^{\mathrm{T}}{ }^{\mathrm{T}}$, isolated from an $H$. marginatum marginatum tick in Morocco, be regarded a separate taxonomic species named Rickettsia aeschlimannii.

Description of Rickettsia aeschlimannii sp. nov. Rickettsia aeschlimannii (ae.schli.man'.ni.i, L. gen. n. aeschlimannii, of Aeschlimann, named after André Aeschlimann, a Swiss zoologist, is an obligate intracellular bacterium of the tick Hyalomma marginatum, which grows in several cell lines (Vero, L929, and Hel). It can be grown in Earle's MEM supplemented with $4 \%$ fetal calf serum and $2 \mathrm{mM} \mathrm{L}$-glutamine at $32^{\circ} \mathrm{C}$. After Giménez staining, this organism is rod shaped (data not shown). As determined by electron microscopy, this rickettsia has features in common with the other SFG rickettsiae. Mouse antisera against this rickettsia show cross-reactivity against antigens of other SFG rickettsiae. MIF, SDS-PAGE, Western immunoblotting, PFGE, PCR-RFLP, and citrate synthase gene and $16 \mathrm{~S}$ rDNA sequencing indicated that this rickettsia is clearly different from all other recognized SFG rickettsial species, the most closely related organisms being $R$. massiliae, $R$. rhipicephali, and strain Bar29. No information is available about the possible pathogenicity of this organism for vertebrate hosts. The geographic distribution of this bacterium is likely to correspond to the areas where $H$. marginatum ticks have been analyzed (Morocco, Zimbabwe, and Portugal).

Type strain. The type strain $\mathrm{MC}^{\mathrm{T}}{ }^{\mathrm{T}}$, isolated from H. marginatum marginatum in Morocco, is held in the collection of the World Health Organization Collaborative Center for Rickettsial Reference in Marseille, France.

\section{ACKNOWLEDGMENT}

We thank Richard Birtles for reviewing the English manuscript.

\section{REFERENCES}

1. Babalis, T., Y. Tselentis, V. Roux, A. Psaroulaki, and D. Raoult. 1994 Isolation and identification of a rickettsial strain related to Rickettsia massiliae in Greek ticks. Am. J. Trop. Med. Hyg. 50:365-372.

1a.Bacellar, F. Personal communication.

2. Bacellar, F., L. R. Regnery, M. S. Núncio, and A. R. Filipe. 1995. Genotypic evaluation of rickettsial isolates recovered from various species of ticks in Portugal. Epidemiol. Infect. 114:169-178.

3. Bailly-Choumara, H., P. C. Morel, and J. Rageau. 1989. Première contribution au catalogue des tiques du Maroc (Acari, Ixodoidea). Bull. Soc. Sci Phys. Nat. Maroc. 54:71-80.

4. Beati, L., J.-P. Finidori, B. Gilot, and D. Raoult. 1992. Comparison of serologic typing, sodium dodecyl sulfate-polyacrylamide gel electrophoresis protein analysis, and genetic restriction fragment length polymorphism analysis for identification of rickettsiae: characterization of two new rickettsial strains. J. Clin. Microbiol. 30:1922-1930.

5. Beati, L., J.-P. Finidori, and D. Raoult. 1993. First isolation of Rickettsia slovaca from Dermacentor marginatus in France. Am. J. Trop. Med. Hyg. 48:257-268.

6. Beati, L., P.-F. Humair, A. Aeschlimann, and D. Raoult. 1994. Identification of spotted fever group rickettsiae isolated from Dermacentor marginatus and Ixodes ricinus ticks collected in Switzerland. Am. J. Trop. Med. Hyg. 51:138148

7. Beati, L., P. J. Kelly, L. A. Matthewman, P. R. Mason, and D. Raoult. 1995. Prevalence of rickettsia-like organisms and spotted fever group rickettsiae in ticks (Acari: Ixodidae) from Zimbabwe. J. Med. Entomol. 32:140-154.

8. Beati, L., O. Péter, W. Burgdorfer, A. Aeschlimann, and D. Raoult. 1993. Confirmation that Rickettsia helvetica sp. nov. is a distinct species of the spotted fever group of rickettsiae. Int. J. Syst. Bacteriol. 43:521-526.

9. Beati, L., and D. Raoult. 1993. Rickettsia massiliae sp. nov., a new spotted fever group rickettsia. Int. J. Syst. Bacteriol, 43:839-840.

10. Beati, L., V. Roux, A. Ortuño, J. Castella, F. Segura Porta, and D. Raoult. 1996. Phenotypic and genotypic characterization of spotted fever group rickettsiae isolated from Catalan Rhipicephalus sanguineus ticks. J. Clin. Microbiol. 34:2688-2694. 
11. Blanc, G., and J. Caminopteros. 1932. Etudes épidémiologiques et expérimentales sur la fièvre boutonneuse, faites à l'Institut Pasteur d'Athènes. Arch. Inst. Pasteur Tunis 20:343-394.

12. Burgdorfer, W. 1970 . Hemolymph test. A technique for detection of rickettsiae in ticks. Am. J. Trop. Med. Hyg. 19:1010-1014.

13. Conor, A., and A. Bruch. 1910. Une fièvre éruptive observée en Tunisie. Bull. Soc. Pathol. Exot. 8:492-496.

14. Dessen, P., C. Fondrat, C. Valencien, and G. Munier. 1990. BISANCE: a French service for access to biomolecular sequence databases. CABIOS 6:355-356.

15. Eremeeva, M., X. Yu, and D. Raoult. 1994. Differentiation among spotted fever group rickettsiae species by analysis of restriction fragment length polymorphism of PCR-amplified DNA. J. Clin. Microbiol. 32:803-810.

16. Eremeeva, M. E., N. M. Balayeva, and D. Raoult. 1994. Purification of rickettsial cultures contaminated by mycoplasmas. Acta Virol. 38:231-233.

17. Eremeeva, M. E., L. Beati, V. A. Makarova, N. F. Fetisova, I. V. Tarasevich N. M. Balaveva, and D. Raoult. 1994. Astrakhan fever rickettsiae: antigenic and genotypic analysis of isolates obtained from human and Rhipicephalus pumilio ticks. Am. J. Trop. Med. Hyg. 51:697-706.

18. Felsenstein, J. 1989. PHYLIP-phylogeny inference package (version 3.2) Cladistics 5:164-166.

19. Fox, G. E., J. D. Wisotzkey, and P. Jurtshuk, Jr. 1992. How close is close: 16S rRNA sequence identity may not be sufficient to guarantee species identity. Int. J. Syst. Bacteriol. 42:166-170.

20. Giménez, D. F. 1964. Staining rickettsiae in yolk-sac cultures. Stain Technol. 39:135-140.

21. Giroud, P., J. Colas-Belcour, R. Pfister, and P. Morel. 1957. Amblyomma Hyalomma, Boophilus, rhipicephalus d'Afrique sont porteurs d'éléments rickettsiens et néorickettsiens et quelquefois des deux types d'agents. Bull. Soc. Pathol. Exot. 50:529-532

22. Heisch, R. B., W. E. Grainger, A. E. Harwey, and G. Lister. 1962. Feral aspects of rickettsial infections in Kenya. Trans. R. Soc. Trop. Med. Hyg. 56:272-286.

23. Hoogstraal, H. 1956. African Ixodoidea. I. Ticks of the Sudan (with special reference to Equatoria Province and with preliminary reviews of the genera Boophilus, Margaropus, and Hyalomma). Bureau of Medicine and Surgery, Department of the U.S. Navy, Washington, D.C

24. Jukes, T. H., and C. R. Cantor. 1969. Evolution of protein molecules, p. 21-132. In H. N. Munro (ed.), Mammalian protein metabolism. Academic Press, Inc., New York, N.Y.

25. Kelly, P. J., L. Beati, P. R. Mason, L. A. Matthewman, V. Roux, and D. Raoult. 1996. Rickettsia africae sp. nov., the etiological agent of African tick bite fever. Int. J. Syst. Bacteriol. 46:611-614.

26. Kelly, P. J., L. Beati, L. A. Matthewman, P. R. Mason, and D. Raoult. 1994 A new pathogenic spotted fever group rickettsia from Africa. J. Trop. Med. Hyg. 97:129-137.

27. Kelly, P. J., and P. R. Mason. 1990. Serological typing of spotted fever group rickettsia isolates from Zimbabwe. J. Clin. Microbiol. 28:2302-2304.

28. Kelly, P. J., D. Raoult, and P. R. Mason. 1991. Isolation of spotted fever group rickettsias from triturated ticks using a modification of the centrifu- gation-shell vial technique. Trans. R. Soc. Trop. Med. Hyg. 85:397-398.

29. Laemmli, U. K. 1970. Cleavage of structural proteins during the assembly of the head of bacteriophage T4. Nature 227:680-685.

30. Lange, J. V., A. G. El Dessouky, E. Manor, A. I. Merdan, and A. F. Azad 1992. Spotted fever rickettsiae in ticks from the Northern Sinai Governate, Egypt. Am. J. Trop. Med. Hyg. 46:546-551.

31. Meskini, M., L. Beati, A. Benslimane, and D. Raoult. 1995. Seroepidemiology of rickettsial infections in Morocco. Eur. J. Epidemiol. 11:655-660.

32. Ouhelli, H., V. S. Pandey, and T. Benzaoui. 1985. Seasonal variation of cattle ticks in a subhumid area of Morocco. Bull. Anim. Health Prod. Afr. 33:207210

33. Péter, O., D. Raoult, and B. Gilot. 1990. Isolation by a sensitive centrifugation cell culture system of 52 strains of spotted fever group rickettsiae from ticks collected in France. J. Clin. Microbiol. 28:1597-1599.

34. Philip, R. N. E. A. Casper, W. Burgdorfer, R. K. Gerloft, L. E. Hughes, and E. J. Bell. 1978. Serologic typing of rickettsiae of the spotted fever group by indirect microimmunofluorescence. J. Immunol. 121:1961-1968.

35. Regnery, R. L., C. L. Spruill, and B. D. Plikaytis. 1991. Genotypic identification of rickettsiae and estimation of intraspecies sequence divergence for portions of two rickettsial genes. J. Bacteriol. 173:1576-1589.

36. Roux, V., and D. Raoult. 1993. Genotypic identification and phylogenetic analysis of the spotted fever group rickettsiae by pulsed-field gel electrophoresis. J. Bacteriol. 175:4895-4904.

37. Roux, V., and D. Raoult. 1995. Phylogenetic analysis of the genus Rickettsia by $16 \mathrm{~S}$ rDNA sequencing. Res. Microbiol. 146:385-396.

38. Roux, V., E. Rydkina, M. Eremeeva, and D. Raoult. Citrate synthase gene comparison, a new tool for phylogenetical analysis and its application for the rickettsiae. Submitted for publication.

39. Saitou, N., and M. Nei. 1987. The neighbor-joining method: a new method for reconstructing phylogenetic trees. Mol. Biol. Evol. 4:406-425.

40. Stackebrandt, E., and B. M. Goebel. 1994. Taxonomic note: a place for DNA-DNA reassociation and 16S rRNA sequence analysis in the present species definition in bacteriology. Int. J. Syst. Bacteriol. 44:846-849.

41. Tissot Dupont, H., J.-P. Cornet, and D. Raoult. 1994. Identification of rickettsiae from ticks collected in the Central African Republic using the polymerase chain reaction. Am. J. Trop. Med. Hyg. 50:373-380.

42. Towbin, A., T. Staehelin, and J. Gordon. 1979. Electrophoretic transfer of proteins from polyacrylamide gels to nitrocellulose sheets: procedure and some applications. Proc. Natl. Acad. Sci. USA 76:4350-4354.

43. Walker, D. H. 1989. Rocky Mountain spotted fever: a disease in need of microbiological concern. Clin. Microbiol. Rev. 2:227-240.

44. Wayne, L. G., D. J. Brenner, R. R. Colwell, P. A. D. Grimont, O. Kandler, M. R. Krichevsky, L. H. Moore, W. E. C. Moore, R. G. E. Murray, E Stackebrandt, M. P. Starr, and H. G. Trüper. 1987. Report of the Ad Hoc Committee on Reconciliation of Approaches to Bacterial Systematics. Int. J. Syst. Bacteriol. 37:463-464.

45. Weiss, E., J. C. Coolbaugh, and J. C. Williams. 1975. Separation of viable Rickettsia typhi from yolk sac and $\mathrm{L}$ cell host components by Renografin density gradient centrifugation. Appl. Microbiol. 30:456-463. 